Review Article

\title{
Safety precautions for otorhinolaryngologists during the COVID-19 pandemic
}

\author{
Soumick Ranjan Sahoo* \\ Department of ENT, ESIC Model Hospital, Beltola, Guwahati, Assam, India \\ Received: 28 June 2020 \\ Revised: 03 August 2020 \\ Accepted: 04 August 2020 \\ *Correspondence: \\ Dr. Soumick Ranjan Sahoo, \\ E-mail: soumicksahoo@gmail.com \\ Copyright: () the author(s), publisher and licensee Medip Academy. This is an open-access article distributed under \\ the terms of the Creative Commons Attribution Non-Commercial License, which permits unrestricted non-commercial \\ use, distribution, and reproduction in any medium, provided the original work is properly cited.
}

\begin{abstract}
As COVID rapidly spreads through respiratory droplets, health care workers who perform aerosol generating diagnostic and therapeutic procedures, such as otolaryngologists-head and neck surgeons, are particularly at risk. In the article guidelines regarding attending a patient in ENT OPD and emergency, endoscopy examination, taking biopsy, operation theatre (OT) setting and precautions and guidelines to be followed while doing ENT and head and neck operations have been discussed based on review of literature.
\end{abstract}

Keywords: COVID-19, Otorhinolaryngology, Fever, Aerosol

\section{INTRODUCTION}

The coronavirus disease 2019 (COVID-19) pandemic has put unprecedented challenges on the medical community. ENT surgeons and other health care workers who perform and participate in examinations and procedures within the head and neck region, ear, nose and airway are at particularly high risk of exposure and infection from aerosol and droplet contamination. ${ }^{1}$

COVID -19 outbreak originated in Wuhan city of China and it has spread all over the world. In India the first case was reported on January 2020 in a student of Kerala with travel history to Wuhan. Since then the number of cases have been rising in India.

The symptoms of COVID-19 are fever, cough, difficulty in breathing, sore throat, body aches, anosmia and loss of taste. In ENT clinics we get a lot of patients with these symptoms. A proportion of the COVID-19 patients are also asymptomatic which is a major concern for healthcare workers and the community.
Many healthcare workers have got affected after coming in contact with COVID patients and hospitals have turned into hotspot. Health statistics from China suggest that 3300 health care workers were infected by early march which included 22 deaths. ${ }^{2,3}$

As otorhinolaryngologists we are at high risk of exposure and therefore proper safety precautions should be taken while seeing patients. A set of recommendations have been suggested after reviewing literature.

\section{General precautionary guidelines while attending ENT patients}

Whenever a patient is seen by an ENT Specialist following guidelines should be followed: one patient at a time should be examined and proper screening of COVID-19 symptoms should be done, patient should sit at a distance from the clinician and he/she should wear mask at all times and sanitize his hands before entering OPD; those with symptoms suggesting possible COVID-19 should be directed to the appropriate self-care or triage mechanism; the use of telephone, video, or telemedicine visits should be considered to maintain relationships with patients and 
to support assessments that can be made without an inperson physical examination; examination should be done by wearing a proper personal protective equipment (PPE); if a patient requires admission his COVID status should be enquired, if the COVID status is not known COVID test to be conducted and patient should be kept in isolation ward until COVID status is known so that other patients do not get infected; and social distancing to be followed in the waiting area of the patients.

\section{Precautions for attending fever patients in otorhinolaryngology head and neck surgery clinic}

Fever is a common symptom in the outpatient department of otorhinolaryngology head and neck surgery. Upper respiratory tract infection diseases, such as influenza, acute tonsillitis, acute sinusitis and acute otitis media, usually initiate with a symptom of fever. Therefore, fever patients, regardless of whether they have been diagnosed as COVID-19 patients or not, should be treated by adequate protected health care workers and the patient has to be sent to COVID 19 screening/triage clinic or sent for COVID testing.

According to the current definition of graded airborne precautions, standard precautions are defined as wearing work clothes, disposable surgical masks, and latex gloves when necessary. ${ }^{4}$ Grade I precautions include wearing work clothes, waterproof medical cap, surgical masks, gowns and latex gloves. Grade II precautions contain wearing waterproof medical caps, medical protective masks (N95 or N99), protective clothing, work suit, antipenetration isolation gown, latex gloves, shoe covers, and anti-fog protective goggles or protective face shield when necessary. Grade III precautions mean that besides all grade II personal protective equipment (PPE) listed above, wearing a comprehensive protective face shield or a powered air-purifying respirators (PAPR) is required. ${ }^{5}$ It is recommended that grade II precautions are needed for fever patients in COVID-19 epidemic areas, and that grade III precautions should be used for COVID-19 suspected or confirmed cases when necessary. ${ }^{5-8}$

\section{Precautions for attending non-fever patients in otorhinolaryngology head and neck surgery clinic}

Those asymptomatic carriers who are within the incubation period are contagious, and becomes an important source of infection. ${ }^{9}$

Health care workers in the department of otorhinolaryngology head and neck surgery are a group of people who are working close to patients' nose and throat. Therefore, as to non-fever patients, it is recommended that health care workers should wear medical protective masks, goggles/protective face shield, and disposable antipermeation isolation gowns in COVID-19 epidemic areas. If the patient is at high risk of splashing, grade III precautions should be warranted to relevant health care workers. ${ }^{8}$

\section{ENDOSCOPY EXAMINATION}

Endoscopic examinations of the nose, sinuses, oropharynx, hypopharynx and larynx are amongst the most common diagnostic procedures and are routinely performed by ENT and head and neck surgeons. They are considered aerosol generating procedures. ${ }^{10}$ Moreover,the nose and nasopharynx have been shown to be reservoirs for high concentrations of the SARS-CoV-2 virus, and after manipulation, viral particles have been shown to be airborne for 3 hours or more. ${ }^{11,12}$ Therefore, it is recommended the same precautions be adopted for mucosal surface endoscopic examinations as for other aerosol-generating procedures.

Examinations should be limited to patients who have a clear indication and need. Again, the examination should be performed by the most experienced personnel available in an expedient fashion.

Routine or lower-priority examinations should be deferred during the pandemic and the PPE should be worn by the clinician.

Specific recommendations additionally include the following: in awake patients adequate topical preparation to make the examination more comfortable is important, however, use of sprays should be avoided, carefully placed pledgets should be used to provide decongestion and anesthesia; topical anesthesia for any office-based intervention of the larynx under the guidance of a laryngoscope or strobolaryngoscope is performed through application of a spray which is considered high risk, therefore office-based biopsy, injection, laser, or other procedures should be delayed if possible; after completion of the examination, the endoscope must be appropriately handled and the endoscope should not be removed from the examination room without a protective cover. ${ }^{1}$

\section{INPATIENT/OUTPATIENT/EMERGENCY HIGH RISK PROCEDURES}

These inpatient, emergency, and outpatient otolaryngology procedures should be handled differently during the pandemic. Otorhinolaryngologists must wear proper PPE and take proper precautions. The following are examples of procedures that in this setting are considered high risk: routine suctioning of patients with a tracheotomy; nasal packing placement, removal, or manipulation; and attempted foreign body removal, deferring may not be possible. If the location is such that it will be particularly challenging to access in an awake patient or if the individual is particularly intolerant of manipulation, performing the removal under general anesthesia may be necessary.

\section{BIOPSY}

Proper PPE must be worn by the ENT doctor while taking biopsy. Following specific guidelines to be followed: 
meticulous preparation of the patient to be done using xylocaine lozenges/gargles, instruments should be properly sterilized in autoclave after usage and in case of vigorous cough during the procedure/after biopsy area needs to be decontaminated before next procedure. ${ }^{13}$

\section{CLEANING AGENTS AND DISINFECTANTS}

Following guidelines have been recommended for cleaning endoscopes, high contact surfaces and ENT ward to prevent infection among healthcare workers and hospital staff: freshly prepared $1 \%$ sodium hypochlorite can be used as a disinfectant for cleaning and disinfection, leaving the solution for a contact time of at least 10 minutes is recommended, ward cleaning should be done with detergent with water or $1 \%$ sodium hypochlorite, high contact surfaces (door and door knobs) should be regularly cleaned with $1 \%$ sodium hypochlorite, sensitive equipment's (BP apparatus, thermometer, endoscopes) should be wiped with $70 \%$ alcohol-based rub/spirit swab before each patient contact and endoscopes can be sterilized by immersing in $2 \%$ glutaraldehyde solution for 20 minutes. ${ }^{13-16}$

\section{Operative procedures-general considerations}

A number of head and neck, otolaryngologic, and oral surgery procedures are high risk owing to exposure of airway and mucosal surfaces and the possibility of generating aerosols. During the pandemic, all elective procedures that can be safely postponed should be delayed.

If an operative procedure is planned, the following considerations are recommended:

\section{COVID-19 status}

If possible, COVID-19 status of the patient should be determined beforehand. If a patient tests positive, a careful assessment of risk to the patient and health care workers should be performed before the operation is recommended. ${ }^{1}$ Operating on mucosal surfaces in a patient who is actively infected generates a great risk for the entire operating room and recovery units and may compromise the patient's ability to recover from the infection.

\section{Operating room setting}

High-risk operations or operations in patients with known COVID-19 should be performed in a designated operating room with negative pressures. ${ }^{1,17}$ Unprotected health care personnel should not be allowed in a room where an aerosol-generating procedure is being or has been conducted. If a patient is known or suspected to have COVID-19, appropriate PPE must be worn by all.

\section{High-risk procedures}

Considering the high viral titers in nasal mucosal, oral, pharyngeal, and pulmonary secretions, any operation that involves these surfaces is high risk to the entire operating room personnel. To our knowledge, bloodborne transmission has not been documented, but aerosolization of blood through the use of energy devices used for control of bleeding and in dissection has been documented.18 These procedures should be considered higher risk. This includes the use of powered devices (e.g. drills and microdebriders). ${ }^{1}$ If a high-risk operation is indicated during the pandemic in a SARS-CoV-2 negative patient or a patient without symptoms or contact, appropriate PPE for all operating room staff is strongly recommended with minimal use of powered devices.

\section{Intubation and extubation}

In all operations, coordination with the anesthesia team is critical. It is advisable that during intubation, all nonessential staff leave the room and only return after the airway is secured. Additionally, all nonessential staff should be out of the room during extubation. Anybody who is present should maintain appropriate PPE.

\section{SPECIFIC OPERATIVE PROCEDURE GUIDELINES}

\section{Endoscopic paranasal sinus and skull base surgery}

These are very high-risk procedures. In general, these procedures should be postponed in patients with COVID19 or those who cannot be tested except in cases of life threatening complications. In negative patients, PPE for all operating room staff is recommended.$^{1,19}$

\section{Thyroidectomy and neck procedures}

Procedures that do not expose mucosal surfaces are lower risk, with the caveat that the use of energy devices can result in aerosolization of the virus from the bloodstream or other gastrointestinal secretions. Patients with COVID19 are likely to have the virus in their bloodstream and feces, based on the experience with SARS, which is also caused by a coronavirus. ${ }^{20,21}$ Proper PPE must be worn by the operating team.

\section{Otologic surgery}

Whether the respiratory mucosa lining the middle ear and mastoid air cell system is involved in COVID-19 is not known yet. ${ }^{1}$ But because the rest of the airway is involved, it appears likely that the lining of the Eustachian tube, middle ear, and mastoid air cell system are all contaminated. ${ }^{22,23}$ Mastoid drilling generates droplets and aerosols which puts the doctor and his operating team at risk and therefore proper PPE must be worn and safety precautions taken. Ideally, any patient undergoing any ear surgery should be tested for COVID-19 preoperatively. If a patient is positive, surgery should be delayed until the patient has cleared the disease except in cases of life threatening complications. 


\section{Tracheostomy}

Performing tracheostomy on patients with suspected or confirmed COVID-19 imposes unique challenges on not only otolaryngologists-head and neck surgeons but the entire health care team. ${ }^{24}$

In nonemergency situations, all cases should be reviewed by a multidisciplinary team, and the risks versus benefits of the procedure for the patient and the entire health care team should be carefully assessed. Additionally, a detailed post-procedure care plan should be established to ascertain the protection of other patients and health care workers. The view points by Tay et al in their journal article outlines many of these considerations. ${ }^{25}$ In general, most tracheostomy procedures should be avoided or delayed (even beyond 14 days) because of the high infectious risks of the procedure and subsequent care until such time as the acute phase of infection has passed, when the likelihood of recovery is high, and when ventilator weaning has become the primary goal of care. Avoiding early tracheostomy in patients with COVID-19 is suggested because of the higher viral load that maybe present at this time. In addition, early tracheostomy was not found to be associated with improved mortality or reduced length of intensive care unit stay in a randomized clinical trial of patients on mechanical ventilation. ${ }^{26}$

Some of the additional procedure specific guidelines are: when feasible, GA following intubation should be considered; if intubation is not feasible, consider superior laryngeal nerve block and inject lignocaine into the trachea prior to incising the trachea to reduce cough; transient apnoea to be maintained during the brief period tracheal incision to cuff inflation of inserted tracheostomy tube; closed suction system to be used and usage to be guarded; double lumen cuffed tube may be used to avoid frequent tube change due to tube blockage postoperatively; heat moisture exchanger (HME) to be attached to tracheostomy tube when patient is shifted to ward and for high risk cases, a triple layer/N95 mask may also be worn over the tracheostomy tube. ${ }^{13}$

\section{CONCLUSION}

As ENT specialists we are at high risk of exposure to COVID Infection. But by following strict safety guidelines in OPD, ward, emergency and operation theatre the risk of exposure and infection could be greatly reduced while providing high levels of care.

Funding: No funding sources Conflict of interest: None declared

Ethical approval: Not required

\section{REFERENCES}

1. Givi B, Schiff BA, Chinn SB, Clayburgh D, Iyer NG, Jalisi S, et al. Safety recommendations for evaluation and surgery of the head and neck during the COVID-
19 pandemic. JAMA Otolaryngol Head Neck Surg. 2020;146(6):579-84.

2. The Lancet. COVID-19: protecting health-care workers. Lancet. 2020;395(10228):922.

3. Shakrawal N, Rajan N. The perils of COVID-19 for otorhinolaryngologists: an overview. Indian J Otolaryngol Head Neck Surg. 2020;1-5.

4. The National Health and Family Planning Commission of People Republic of China. The prevention and control standards of airbrone transmitted nosocomial infection. 2016. Available at: http://www.whcdc.org/wcs/Upload/201808/5b84eeb 4d8b5b.pdf. Accessed on 25 May 2020.

5. Wei Q, Ren Z. The disinfection measures of 2019$\mathrm{nCoV}$ epidemic focus. Chin $\mathrm{J}$ Disinfection. 2020;37(1):59-62.

6. Ni XG. The control procedure of nasopharyngolarygnoscope examination during COVID-19 outbreak. 2020. Available at: http://wx.entlianmeng.com/info/view/534?rZ1234. Accessed on 20 May 2020.

7. General office of the National Health Commission. The Transmission Route and Prevention Manual of COVID-19. 2020. Available at: http://www.nhc.gov.cn/jkj/s3578/202001/9e730600 17d744aeafff $8834 \mathrm{fc} 0389 \mathrm{f} 4$.shtml. Accessed on 20 May 2020

8. Xu K, Lai X, Liu Z. Suggestions on the prevention of COVID-19 for health care workers in department of otorhinolaryngology head and neck surgery, World Journal of Otorhinolaryngology-Head and Neck Surgery. 2020.

9. General office of the National Health Commission. The diagnosis and treatment protocol of COVID-19 (the temporary sixth edition). 2020. Available at: http://www.nhc.gov.cn/yzygj/s7653p/202002/8334a 8326dd94d329df351d7da8aefc2/files/. Accessed on 20 May 2020.

10. US Centers for Disease Control and Prevention.Interim infection prevention and control recommendations for patients with suspected or confirmed coronavirus disease (COVID-19) in healthcare settings. 2020. Available at: https://www.cdc.gov/coronavirus/2019-ncov/ infection-control/control-recommend-ations.html. Accessed on 23 March 2020.

11. Zou L, Ruan F, Huang M, Liang L, Huang H, Hong $\mathrm{Z}$, et al. SARS-CoV-2 viral load in upper respiratory specimens of infected patients. $\mathrm{N}$ Engl J Med. 2020;382(12):1177-9.

12. van Doremalen $\mathrm{N}$, Bushmaker $\mathrm{T}$, Morris $\mathrm{DH}$, Holbrook MG, Gamble A, Williamson BN, et al. Aerosol and surface stability of SARS-CoV-2 as compared with SARS-CoV-1. N Engl J Med. 2020;382(16):1564-7.

13. Guidelines for safe ENT practice in COVID 19. 2020. Available at: https://www.mohfw. gov.in/pdf/ENTCOVID0306/pdf. Accessed on 03 June 2020. 
14. Infection prevention and control guidelines for 2019nCoV (COVID-19). 2020. Available at: https://www.aiims.edu/images/pdf/notice/Updated_ COVID_19_HIC_SUPPLEMENT_VERSION_ 1.2. Accessed on 30 March 2020.

15. COVID-19: Guidelines on disinfection of common public places including offices. Available at: https://www.mohfw.gov.in/pdf/Guidelinesondisinfe ctionofcommonpublicplacesincludingoffice.

Accessed on 20 May 2020.

16. Guideline for Disinfection and Sterilization in Healthcare Facilities. 2008. Available at: https://www.cdc.gov/infectioncontrol/guidelines/disi nfection/. Accessed on 10 May 2020.

17. American College of Surgeons. COVID-19: guidance for triage of non-emergent surgical procedures. Available at: https://www.facs.org/ covid-19/clinical-guidance/triage. Accessed on 23 March 2020.

18. Zheng MH, Boni L, Fingerhut A. Minimally invasive surgery and the novel coronavirus outbreak: lessons learned in China and Italy. Ann Surg. 2020;272(1):56.

19. Patel ZM, Miranda JF, Hwang PH, Nayak JV, Dodd $\mathrm{R}$, Sajjadi H, et al. Letter: precautions for endoscopic transnasal skull base surgery during the COVID-19 pandemic. Neurosurgery. 2020.

20. Isakbaeva ET, Khetsuriani N, Beard RS, Peck A, Erdman D, Monroe SS, et al. SARS investigation group. SARS-associated coronavirus transmission, United States. Emerg Infect Dis. 2004;10(2):225-31.

21. Ding Y, He L, Zhang Q, Che X, Hou J, Wang H, Shen $\mathrm{H}$, et al. Organ distribution of severe acute respiratory syndrome (SARS) associated coronavirus (SARS$\mathrm{CoV})$ in SARS patients: implications for pathogenesis and virus transmission pathways. J Pathol. 2004;203(2):622-30.

22. Pitkäranta A, Virolainen A, Jero J, Arruda E, Hayden FG. Detection of rhinovirus, respiratory syncytial virus, and coronavirus infections in acuteotitis media by reverse transcriptase polymerase chain reaction. Pediatrics. 1998;102(2):291-5.

23. Heikkinen T, Thint M, Chonmaitree T. Prevalence of various respiratory viruses in the middle ear during acute otitis media. N Engl J Med.1999;340(4):260-4.

24. Murthy S, Gomersall CD, Fowler RA. Care for critically ill patients with COVID-19. JAMA. 2020;325(15):1499-500.

25. Tay JK, Khoo MLC, Loh WS. Surgical considerations for tracheostomy during the COVID19 pandemic: lessons learned from the severe acute respiratory syndrome outbreak. JAMA. 2020;146(6):517-8.

26. Young D, Harrison DA, Cuthbertson BH, Rowan K. Effect of early versus late tracheostomy placement on survival in patients receiving mechanical ventilation: the TracMan randomized trial. JAMA. 2013;309(20):2121-9.

Cite this article as: Sahoo SR. Safety precautions for otorhinolaryngologists during the COVID-19 pandemic. Int J Otorhinolaryngol Head Neck Surg. 2020;6:1757-61. 